\title{
DVIRATININKŲ ŠIRDIES SUSITRAUKIMŲ DAŽNIO PRIKLAUSOMYBE் NUO GALIOS SUKANT VELOERGOMETRĄ SKIRTINGU TEMPU
}

\author{
Arvydas Stasiulis, Gintautas Volungevičius \\ Lietuvos kūno kultūros akademija, Kaunas, Lietuva
}

\begin{abstract}
Arvydas Stasiulis. Profesorius biomedicinos mokslų daktaras. Lietuvos kūno kultūros akademijos Taikomosios fiziologijos ir kineziterapijos
\end{abstract} katedros vedejjas. Mokslinių tyrimų kryptis — sportininkų aerobinio pajėgumo tyrimas.

\section{SANTRAUKA}

Tyrimo tikslas - palyginti dviratininku širdies susitraukimu dažnio (ŠSD) priklausomybę nuo galios sukant veloergometrq skirtingu tempu.

15 didelio meistriškumo dviratininku vyru (amžius - 23,0 (1,41) m., ügis - 1,77 (0,04) m, svoris - 66,3 (7,1) kg) „, Monark 834E“ (Švedija) veloergometru tris kartus atsitiktine tvarka atliko kas minutę didinama krūvi. Pedalu sukimo tempas - 60, 80 arba 100 apsuku per minutę. ŠSD registruotas viso krūvio ir atsigavimo metu naudojant telemetrini ŠSD matuokli Polar S810i (Polar, Suomija). Buvo analizuojama vidutiniu ŠSD reikšmin per paskutines 10 kiekvieno krūvio sekundžiu priklausomybe nuo darbo galios, surandamas ŠSD nuokrypio taškas (ŠSD ${ }_{N T}$ ) bei ji atitinkančios $\check{S} S D$ ir darbo galios reikšmès.

Nustatyta, kad ŠS $D_{N T}$ mažejo atliekant didinamo krūvio testa didesniu tempu, tuo tarpu ŠSD reikšmès pasiekus šiq galiq buvo labai panašios ir nuo pedalu sukimo tempo nepriklause. Didžiausias didinamo krūvio metu pasiektas galingumas nesiskyrè, o maksimalus ŠSD buvo mažiausias sukant pedalus 60 aps. / min tempu. ŠSD procentinis dydis (\% nuo maksimalaus) pasiekus $\check{S} S D_{N T}$ taip pat buvo panašus ir sieke apie $86 \%$ maksimalaus. ŚSD dirbant submaksimaliu galingumu visada buvo mažiausias sukant pedalus 60 aps. / min tempu. Kaip rodo tiesinès regresijos koeficientai, ŠSD prieaugio tempai didèjant krūviui tiesinèje ŠSD ir galios priklausomumo dalyje nesiskyrè sukant pedalus skirtingu tempu.

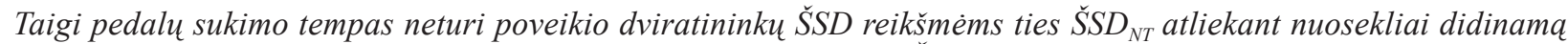
krūvì veloergometru, tačiau didejjant pedalu sukimo tempui dideja ir ŠSD reikšmès submaksimalaus ir net maksimalaus intensyvumo aerobinio krūvio metu, todèl galia ties $S$ SD ${ }_{N T}$ sumažèja. Tai gali büti susije su miokardo funkcijos reguliavimo pokyčiais pasiekus pakankamai dideli susitraukimu dažni.

Raktažodžiai: širdies susitraukimu dažnis, širdies susitraukimu dažnio nuokrypio taškas, pedalu sukimo tempas, didinamo krūvio testas.

\section{IVADAS}

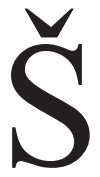
irdies susitraukimų dažnis (ŠSD) yra vienas informatyviausių rodiklių nustatant fizinio krūvio poveiki sportininko organizmui ir reakciją i judesių dažnumą bei galią. Dviratininku tyrimo rezultatai dèl skirtingų protokolu gausos dažnai būna nepatikimi (Faria et al., 2005). Stokojama specialių tyrimų, analizuojančių dviratininkų rezultatų ir neadekvataus širdies darbo ryši. Reikè- tų atlikti ir tokių tyrimų, kuriais būtų išsiaiškinta, ar širdies darbas, o gal $\mathrm{O}_{2}$ suvartojimas apriboja dviratininkų rezultatus, esant tokiam intensyviam darbui, kokị atlieka profesionalūs dviratininkai (Faria et al., 2005).

Širdies susitraukimų dažnio (ŠSD) priklausomybè nuo fizinio krūvio galios nèra visiškai tiesinè. ŠSD prieaugis nuosekliai didinamo krū- 


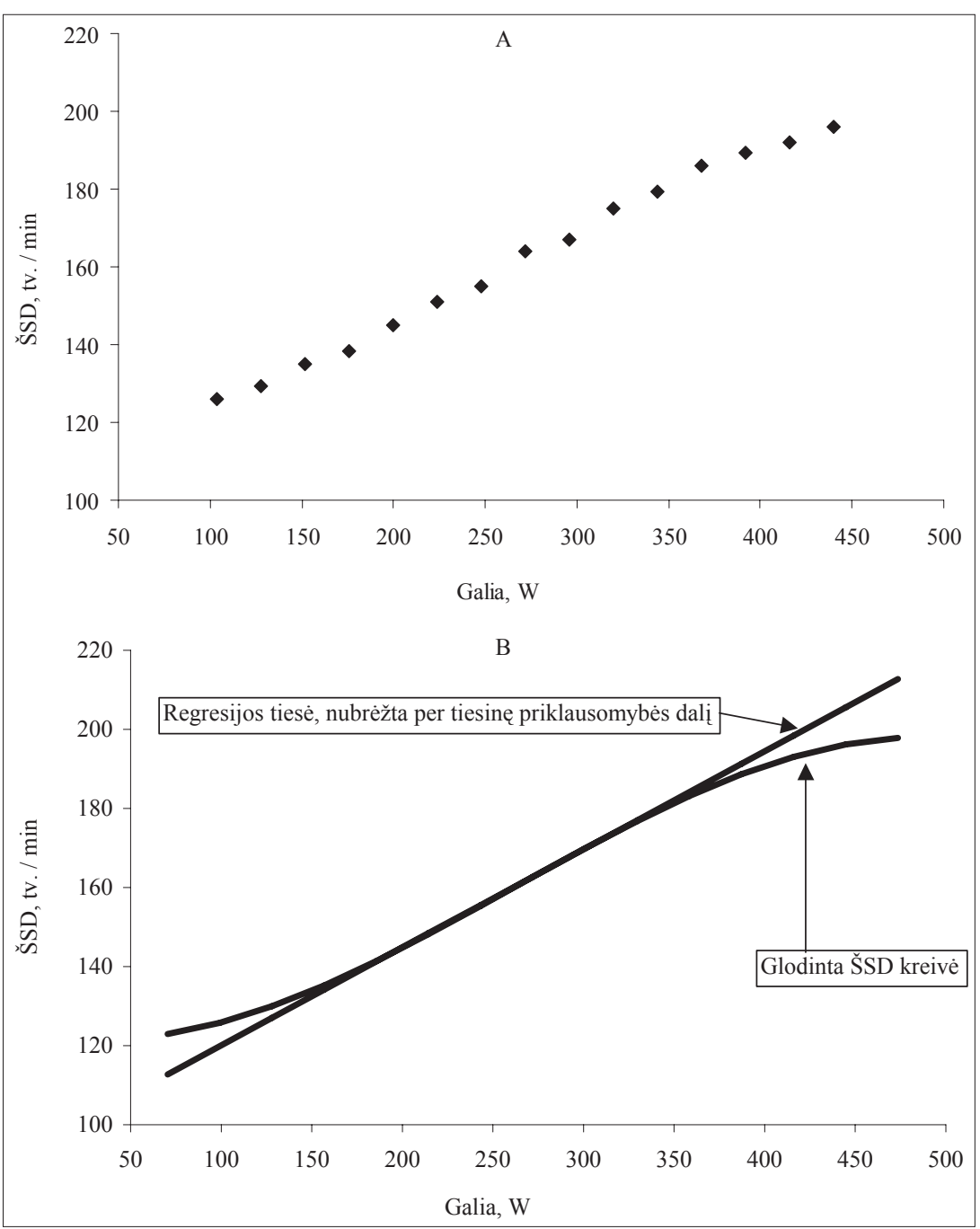

1 pav. Vieno tiriamojo ŠSD kaita pakopomis didinamo krūvio metu (A), ŠSD ir galios priklausomumo analizès nustatant ŠSD nuokrypio tašką pavyzdys (B)

vio pabaigoje paprastai sulètèja (Wahlund et al., 1948; Brooke et al., 1968; Conconi et al., 1982; Hofmann et al., 1994). Krūvis, virš kurio ŠSD priklausomybė nuo galios pasikeičia, vadinamas ŠSD nuokrypio tašku ( ŠSD $_{\mathrm{NT}}$ ) (Bodner, Rhodes, 2000). Jis paprastai pasireiškia ŠSD padidejus iki 88-94\% nuo maksimalaus ((Bodner, Rhodes, 2000). ŠSD ${ }_{\mathrm{NT}}$ būdingas daugeliui asmenu, atliekančių nuosekliai didinamą fizinị krūvị, tarp jų ir dviratininkams (Lucia et al., 1999, 2002).

Nustatyta, kad deguonies suvartojimo, širdies ir kraujagyslių sistemos funkcinių rodiklių reikšmès veloergometrinio krūvio metu priklauso nuo pedalų sukimo tempo (Moore et al., 2008). Vieni autoriai nustatè, kad sukant veloergometrą greitesniu tempu, bet ta pačia galia, ŠSD būna didesnis (Moore et al., 2008), kiti nepastebèjo reikšmingo pedalų sukimo tempo poveikio ŠSD atliekant skirtingo (Chavarren, Calbet, 1999) ar $30 \mathrm{~min}$ pastovaus intensyvumo krūvị (Lepers et al., 2001). Taigi duomenys apie pedalų sukimo tempo poveiki ŠSD yra prieštaringi. Nèra tyrimų, kurių metu būtų nagrinèta, kaip pedalų sukimo tempas veikia galią ir ŠSD ties $\breve{S}_{S} D_{\mathrm{NT}}$ atliekant nuosekliai didinamą krūvi veloergometru.

Šio tyrimo tikslas - palyginti dviratininkų ŠSD priklausomybę nuo galios sukant veloergometro pedalus skirtingu tempu.

\section{TYRIMO METODIKA}

Tiriamieji. 15 didelio meistriškumo dviratininkų vyrų sutiko būti tiriami. Jų vidutinis amžius — 23,0 $(1,41)$ m., ūgis - 1,77 $(0,04)$ m, svoris - 66,3 $(7,1) \mathrm{kg}$. Kad pratybos būtų lengvesnès, testavimo išvakarèse tiriamujų buvo prašoma testavimo dieną visiškai nesimankštinti ir nevalgyti mažiausiai dvi valandas prieš tyrimus. Atskiri testavimai vyko panašiu paros metu, o tarp jų buvo ne mažesnè kaip dviejų dienų pertrauka.

Nenutrūkstamo pakopomis didinamo krūvio testas. Kiekvienas tiriamasis „Monark 834E“ ( ̌́vedija) veloergometru tris kartus atsitiktine tvarka atliko kas minutę didinamą krūvị. Pedalų sukimo tempas - 60,80 arba 100 apsuku per minutę. Po vienos minutès darbo, esant nuliniam 


\begin{tabular}{|c|c|c|c|c|}
\hline \multirow{11}{*}{$\begin{array}{l}\text { Lentelè. ŠSD ir galios } \\
\text { rodikliai (kvadratiniai } \\
\text { nuokrypiai) veloergome- } \\
\text { trinio nuosekliai didina- } \\
\text { mo krūvio metu, sukant } \\
\text { pedalus skirtingu tempu }\end{array}$} & Rodiklis $\quad$ Sukimo tempas & 60 aps. / min & 80 aps. / min & 100 aps. / min \\
\hline & ŠSD nuokrypio taškas, W & $260,9 \pm 49,2$ & $255,3 \pm 32,1$ & $248,7 \pm 28,9 *$ \\
\hline & Santykinis ŠSD nuokrypio taškas, W / kg & $3,92 \pm 0,55$ & $3,85 \pm 0,31$ & $3,76 \pm 0,30 *$ \\
\hline & ŠSD pasiekus nuokrypio tašką, tv. / min & $168,1 \pm 8,2$ & $168,7 \pm 7,1$ & $166,9 \pm 10,3$ \\
\hline & ŠSD pasiekus nuokrypio tašką, \% nuo maks. & $87,3 \pm 2.7$ & $85.6 \pm 2.0$ & $86.4 \pm 2.9$ \\
\hline & Didžiausias pasiektas galingumas, $\mathrm{W}$ & $388,7 \pm 38,0$ & $384,9 \pm 32,0$ & $388,0 \pm 35,5$ \\
\hline & Didžiausias pasiektas galingumas, W / kg & $5,90 \pm 0,63$ & $5,84 \pm 0,58$ & $5,88 \pm 0,54$ \\
\hline & Maksimalus ŠSD, tv. / min & $193,4 \pm 5,9$ & $197,0 \pm 6,7$ & $197,4 \pm 7,5^{*}$ \\
\hline & ŠSD 1 min po krūvio, k. / min & $160,1 \pm 9,4$ & $174,8 \pm 10,2 *$ & $163,2 \pm 9,0 * \#$ \\
\hline & ŠSD 1 min po krūvio, \% nuo maks. & $82,8 \pm 22,8$ & $88,7 \pm 4,0^{*}$ & $82,9 \pm 22,8 * \#$ \\
\hline & ŠSD 5 min po krūvio, tv. / min & $111,0 \pm 9,6$ & $110,9 \pm 11,2$ & $110,8 \pm 9,8$ \\
\hline \multirow{6}{*}{$\begin{array}{l}\text { Pastaba. } *-p<0,05, \\
\text { lyginant su } 60 \text { aps. / min; } \\
\#-p<0,05, \text { lyginant su } \\
80 \text { aps. / min; a ir b atitin- } \\
\text { kamai - ŠSD priklauso- } \\
\text { mybès nuo galios tiesinę } \\
\text { dali aproksimuojančios } \\
\text { tiesinès regresijos lygties } \\
\text { laisvasis narys ir regresijos } \\
\text { koeficientas. }\end{array}$} & ŠSD 5 min po darbo, $\%$ nuo maks. & $57,3 \pm 3,8$ & $56,3 \pm 5,6$ & $56,1 \pm 4,2$ \\
\hline & a & $89,7 \pm 20,7$ & $90,1 \pm 15,8$ & $96,7 \pm 18,7 * \#$ \\
\hline & $\mathrm{b}$ & $0,300 \pm 0,049$ & $0,310 \pm 0,061$ & $0,290 \pm 0,046$ \\
\hline & ŠSD, kai krūvis $150 \mathrm{~W}$ & $134,5 \pm 15,6$ & $136,6 \pm 10,5$ & $140,7 \pm 14,3^{*}$ \\
\hline & ŠSD, kai krūvis $200 \mathrm{~W}$ & $149,5 \mathrm{v} 14,3$ & $152,1 \pm 10,1$ & $155,3 \pm 13,2^{*}$ \\
\hline & ŠSD, kai krūvis $250 \mathrm{~W}$ & $164,4 \pm 13,4$ & $167,6 \pm 10,5$ & $169,9 \pm 12,6^{*}$ \\
\hline
\end{tabular}

smagračio pasipriešinimui, buvo nustatomas pradinis 90, 104 ar $100 \mathrm{~W}$ krūvis, kuris toliau kas minutę buvo didinamas 30, 24 ar $30 \mathrm{~W}$ (atitinkamai minant pedalus 60, 80 arba 100 aps. / min tempu). Testas buvo tęsiamas tol, kol tiriamieji nebepajègdavo tęsti krūvio reikiamu tempu.

$\breve{S S S D}$ registravimas ir analize. ŠSD buvo registruojamas viso krūvio ir atsigavimo metu naudojant telemetrini S̆SD matuoklị Polar S810i (Polar, Suomija). Vèliau užregistruoti duomenys buvo perkeliami i kompiuterio programą „Polar performance“ ir „Microsoft Excel“". Analizuota vidutinių ŠSD reikšmių per paskutines 10 kiekvieno krūvio sekundžiu priklausomybè nuo darbo galios. Tuo tikslu ŠSD reikšmès buvo pavaizduojamos grafiškai kaip darbo galios funkcija, duomenys glodinami taikant 3 eilès daugialaipsnę funkcija, per tiesinę priklausomybès dalį brěžiama tiesè (pritaikius tiesinę funkciją) ir surandamas $\mathrm{S}_{\mathrm{SD}}$ bei ji atitinkančios ŠSD, darbo galios reikšmès (1 pav.). Pagal tiesinès regresijos lygti buvo apskaičiuojamos ŠSD reikšmès kintant darbo galiai nuo 100 iki $225 \mathrm{~W}$, norint palyginti ŠSD reikšmes, kai galia ta pati, bet skirtingas pedalu sukimo tempas.

Matematinè statistika. Buvo apskaičiuojami duomenų vidurkiai ir standartiniai nuokrypiai. Rodikliu reikšmès sukant pedalus skirtingų tempu palygintos Studento $t$ kriteriju taikant priklausomoms imtims. Pasirinktas statistinio reikšmingumo lygmuo $-\mathrm{p}<0,05$.

\section{REZULTATAI}

Kaip rodo lentelès duomenys, $\breve{S S D}_{\mathrm{NT}}$ mažejo atliekant didinamo krūvio testą didesniu tempu, tuo tarpu ŠSD reikšmès pasiekus šią galią buvo labai panašios ir nuo pedalų sukimo tempo nepriklausè. Didžiausias didinamo krūvio metu pasiektas galingumas nesiskyrè, o maksimalus ŠSD buvo mažiausias sukant pedalus 60 aps. / min tempu. ŠSD procentinis dydis (\% nuo maksimalaus) pasiekus $\mathrm{SSD}_{\mathrm{NT}}$ taip pat buvo panašus ir siekè apie $86 \%$ maksimalaus. ŠSD dirbant submaksimaliu galingumu visada buvo mažiausias sukant pedalus 60 aps. / min tempu ( 2 pav.). Kaip rodo tiesinès regresijos koeficientai, ŠSD prieaugio tempai didejjant krūviui tiesinèje ŠSD ir galios priklausomumo dalyje, nesiskyrè sukant pedalus skirtingu dažnumu (žr. lent.).

\section{REZULTATŲ APTARIMAS}

Šiuo tyrimu nustatyta, kad atliekant nuosekliai didinamą krūvị veloergometru pedalų sukimo tempas neturi poveikio ŠSD reikšmėms ties $\mathrm{S}_{\mathrm{SD}} \mathrm{NT}_{\mathrm{NT}}$, tačiau didèjant tempui dideja ir ŠSD reikšmès submaksimalaus ir net maksimalaus intensyvumo aerobinio krūvio metu, todèl galia ties $\mathrm{S} \mathrm{SD}_{\mathrm{NT}}$ sumažèja.

Tyrimo duomenys patvirtino, kad $\mathrm{SSD}_{\mathrm{NT}}$ atliekant nuosekliai didinamą fizini krūvị būdingas ir dviratininkams (Lucia et al., 1999, 2002). 


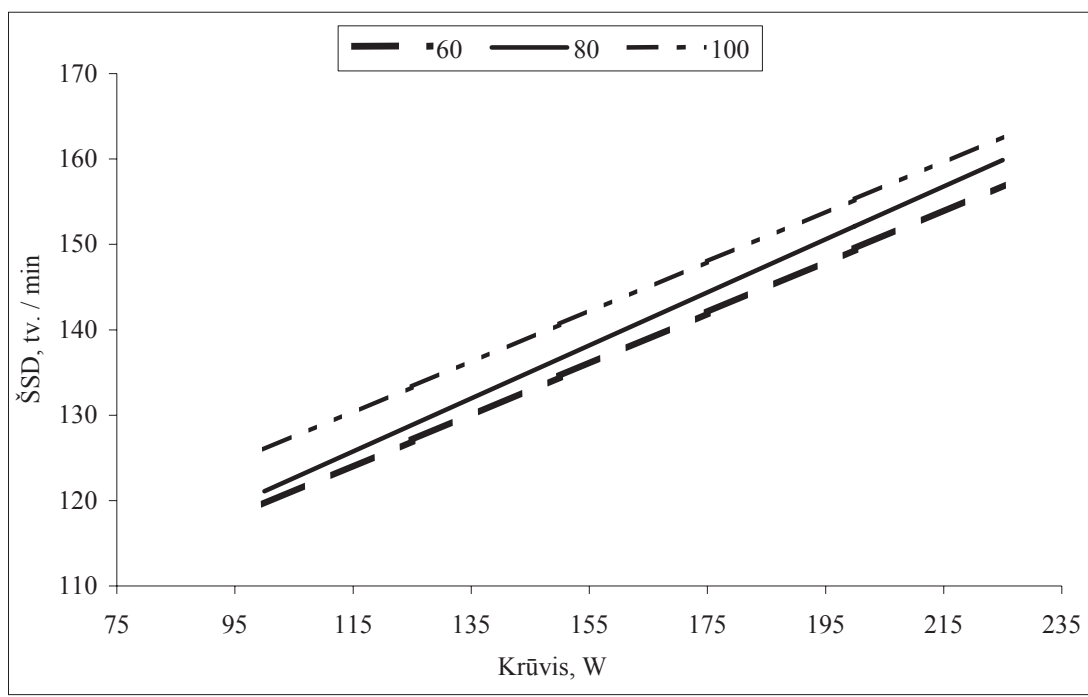

2 pav. Vidutinės ŠSD reikšmės esant submaksimaliam darbo intensyvumui ir jų priklausomumas nuo pedalų sukimo dažnio pakopomis didinamo krūvio metu

J. L. Moore su bendraautoriais (2008) pastebejo, kad sukant pedalus greitesniu tempu ŠSD padideja esant submaksimaliam darbo galingumui (Moore et al., 2008). Tiesa, kiti autoriai nepastebejjo reikšmingo pedalu sukimo tempo poveikio ŠSD atliekant skirtingo (Chavarren, Calbet, 1999) ar $30 \mathrm{~min}$ pastovaus intensyvumo krūvi (Lepers et al., 2001). Manoma, kad esant didesniam pedalu sukimo tempui dèl padidejjusio deguonies poreikio padideja ir minutès kraujo tūris, kuri savo ruožtu padidina išaugęs sistolinis kraujo tūris dèl padidejjusio veninio kraujo pritekejjimo, t. y. geresnio griaučiu raumenu siurblio funkcionavimo sukant pedalus didesniu tempu (Gotshall et al., 1996). Visgi tikètina, kad minutès kraujo tūris labiau arba tiek pat padidèja ir dèl ŠSD prieaugio. Tai parodè dviratininkų, dirbančiu submaksimalia galia, kraujotakos tyrimo duomenys (Moore et al., 2008). Idomu tai, kad ŠSD ${ }_{\mathrm{NT}}$ nesikeičia nepaisant ŠSD ir galios santykio pokyčio, t. y. ŠSD $_{\mathrm{NT}}$ pasireiškia esant panašiam absoliučiam ir santykiniam ŠSD. Galima manyti, kad šio nuokrypio taško poreiškis priklauso nuo didinamo krūvio metu pasiekto ŠSD, kuris daugelio asmenų siekia 88-94\% maksimalaus (Bodner, Rhodes, 2000). F. Conconi ir kt. (Conconi et al., 1982, 1996) iškèlè prielaidą, kad suaktyvejus anaerobinei ATP resintezei palengveja oksihemoglobino disociacija, dèl to kraujotakos veiksmingumas padidèja, ir tai sumažina didesnio ŠSD poreikị. Deja, cituojami autoriai savo prielaida grindè tuo, kad $\mathrm{S} \mathrm{SD}_{\mathrm{NT}}$ dažnai sutampa su anaerobiniu slenksčiu, nors tai dar neirodo šių fenomenu priežastinio ryšio. Neseniai atliktas tyrimas parodè, kad $\mathrm{S} \mathrm{SD}_{\mathrm{NT}}$ labiau susijęs su hiperkalemija, būdinga pasiekus toki darbo intensyvumą (Lucia et al., 2002). Yra duomenų, kad $\mathrm{S}_{\mathrm{S}} \mathrm{D}_{\mathrm{NT}}$ gali būti susijęs su miokardo funkcija pasiekus pakankamai dideli krūvio intensyvumą ir labai padidejus ŠSD (Pokan et al., 1993, 1999; Hofman et al., 1994; Foster et al., 1999). Manome, kad gauti duomenys labiausiai atitinka šią hipotezę, nes ŠSD dydis, o ne krūvio intensyvumas yra svarbesnis $\breve{S} \mathrm{SD}_{\mathrm{NT}}$ poreiškiui.

\section{IŠVADA}

Pedalų sukimo tempas neturi poveikio dviratininkų ŠSD reikšmėms ties ŠSD $\mathrm{ST}_{\mathrm{NT}}$ atliekant nuosekliai didinamą krūvị veloergometru, tačiau didejant tempui didejja ir ŠSD reikšmès submaksimalaus ir net maksimalaus intensyvumo aerobinio krūvio metu, todèl galia ties ŠSD $\mathrm{NT}_{\mathrm{NT}}$ sumažèja.

\section{LITERATŪRA}

Bodner, M. E., Rhodes, E. C., (2000) A review of the concept of the heart rate deflection point Sports Medicine, 30, 31-46.

Brooke, J. D., Hamley, E. J., Thomson, H. (1968). The relationship of heart rate to physical work. Journal of Physiology (London), 167, 61-63.

Chavarren, J., Calbet, J. (1999). Cycling efficiency and pedalling frequency in road cyclists. European Journal of Applied Physiology, 80, 555-563.
Conconi, F., Ferrari, M., Ziglio, P. G. et al. (1982). Determination of the anaerobic threshold by a noninvasive field test in runners. Journal of Applied Physiology, 152, $869-873$.

Conconi, F., Grazzi, G., Casoni, I. et al. (1996). The Conconi test: Methodology after 12 years of application. International Journal of Sports Medicine, 17, 509-519.

Faria E. W., Daryl, D. L., Faria, I. E. (2005). The science of cycling: Physiology and training. Part 1. Sports Medicine, 35 (4), 286-312. 
Foster, C., Spatz, P., Georgakopoulos, N. (1999) Left ventricular function in relation to the heart rate performance curve. Clinical Exercise Physiology, 1, 29-32.

Hofmann, P., Pokan, R., Preidler, K. et al. (1994). Relationship between heart rate threshold, lactate turn point and myocardial function. International Journal of Sports Medicine, 15, 232-237.

Lepers, R., Millet, G. Y., Maffiuletti, N. A., Hausswirth, C., Brisswalter, J. (2001). Effect of pedalling rates on physiological response during endurance cycling. European Journal of Applied Physiology, 85 (3-4), $392-395$.

Lucía, A., Carvajal, A., Boraita, A. et al. (1999). Heart dimensions may influence the occurrence of the heart rate deflection point in highly trained cyclists. British Journal of Sports Medicine, 33, 387-392.

Lucía, A., Hoyos, J., Santalla, A. et al. (2002). Lactic acidosis, potassium, and the heart rate deflection point in professional road cyclists. British Journal of Sports Medicine, 36, 113-117.

Moore, J. L., Shaffrath, J. D., Casazza, G. A., Stebbins, C. L. (2008). Cardiovascular effects of cadence and workload. International Journal of Sports Medicine, 29, 116-119.

Pokan, R., Hofmann, P., Preidler, K. et al. (1993). Correlation between inflection of heart/rate work performance curve and myocardial function in exhausting cycle ergometer exercise. European Journal of Applied Physiology, 67, 385-388.

Pokan, R., Hofmann, P., Von Duvillard, S. P. et al. (1998). The heart rate performance curve and left ventricular function during exercise in patients after myocardial infarction. Medicine and Science in Sports and Exercise, 30, 1475-1480.

Wahlund, H. (1948). Determination of the physical working capacity. Acta Medicine Scandinavia, 215, 1-78.

\title{
RELATIONSHIP BETWEEN HEART RATE AND POWER IN CYCLISTS PEDALLING WITH DIFFERENT CADENCE
}

\author{
Arvydas Stasiulis, Gintautas Volungevičius \\ Lithuanian Academy of Physical Education, Kaunas, Lithuania
}

\begin{abstract}
The aim of this study was to compare the relationship between heart rate (HR) and power during the test on a cycle ergometry with increasing load test with different pedalling cadence in cyclists.

15 cyclists with high level of performance (age $-23.0(1.41)$ years, height $-1.77(0.04) \mathrm{m}$, weight $66.3(7.1) \mathrm{kg}$ ) performed a test on the „Monark 834E“ (Sweden) cycle ergometer with the load increasing every minute. On different testing days the cadence was 60,80 or $100 \mathrm{rpm}$. HR was recorded continuously using Polar S810i (Polar, Finland) HR monitor. The relationship between average HR during the last $10 \mathrm{~s}$ of each workload and the power was analysed and HR deflection point was determined.

The results showed that HR deflection point decreased with increasing pedalling cadence, but HR values at this point remained unchanged and did not depend on pedalling cadence. Peak power during the increasing load test was also similar at all cadencies. Maximal HR was significantly higher at cadency $100 \mathrm{rpm}$. Relative HR values (expressed in percent of maximal values) were not significantly different at the cadencies performed and were approximately $86 \%$ of maximal HR. HR at submaximal work intensities was lowest at cadence of $60 \mathrm{rpm}$.

In conclusion, the HR at HR deflection point is not influenced by pedalling cadence during the cycle ergometry test with increasing load, but HR values at submaximal and maximal aerobic intensities increase with increasing pedalling cadence, so the power at HR deflection point decreases. This may be associated with the changes of myocardial function regulation when the subject's HR reaches a certain high level.
\end{abstract}

Keywords: heart rate, heart rate deflection point, pedalling cadence, increasing load test.

Gauta 2008 m. liepos $11 \mathrm{~d}$.

Received on July 11, 2008

Priimta 2008 m. rugsèjo $9 \mathrm{~d}$.

Accepted on September 9, 2008
Gintautas Volungevičius

Lietuvos kūno kultūros akademija

(Lithuanian Academy of Physical Education)

Sporto g. 6, LT-44221 Kaunas

Lietuva (Lithuania)

Tel +37037302671

E-mail g.volungevicius@lkka.lt 